\title{
BREAST-FEEDING AND ACUTE APPENDICITIS - A PROSPECTIVE CORRELATIVE STUDY OF BREAST- FEEDING AS A DISEASE MODIFYING FACTOR
}

\author{
Raghupathy1, Thangamani², Sabreena ${ }^{3}$, Sathish Kailasam ${ }^{4}$, Arikrisknan Vaithiswaran ${ }^{5}$ \\ 1 Professor, Department of General Surgery, Chengalpattu Medical College and Hospital, Chengalpattu. \\ ${ }^{2}$ Associate Professor, Department of General Surgery, Chengalpattu Medical College and Hospital, Chengalpattu. \\ ${ }^{3}$ Assistant Professor, Department of General Surgery, Chengalpattu Medical College and Hospital, Chengalpattu. \\ 4Junior Resident, Department of General Surgery, Chengalpattu Medical College and Hospital, Chengalpattu. \\ 5Junior Resident, Department of General Surgery, Chengalpattu Medical College and Hospital, Chengalpattu.
}

\section{ABSTRACT}

\section{BACKGROUND}

Acute appendicitis is one of the commonest reason for acute abdomen which needs surgery and so to study the risk factors for the cause of appendicitis this study has been conducted.

\section{MATERIALS AND METHODS}

A prospective study of all 68 cases admitted to Chengalpattu Medical College and Hospital, Tamilnadu, between 1 January and 30 November 2016 with proper consent.

\section{RESULTS}

$88 \%$ of the people affected with acute appendicitis were breastfed less than or equal to 12 months.

\section{CONCLUSION}

The risk of developing appendicitis is higher among children who never received EBF and who were breastfed for less than 12 months.

\section{KEYWORDS}

Exclusive Breast-Feeding, Acute Appendicitis, Risk Factor.

HOW TO CITE THIS ARTICLE: Raghupathy, Thangamani, Sabreena, et al. Breast-feeding and acute appendicitis - A prospective correlative study of breast-feeding as a disease modifying factor. J. Evolution Med. Dent. Sci. 2017;6(1):30-32, DOI: $10.14260 /$ Jemds/2017/9

\section{BACKGROUND}

Acute appendicitis is the commonest reason for abdominal surgery in many countries, but its cause is unknown. The hygiene hypothesis attributes the rise in appendicitis that occurred in the United Kingdom at the beginning of this century to improvements in sewage disposal and water supplies in the late 19th century. These improvements in hygiene greatly reduced the exposure of infants to enteric organisms that program the immune system of the gut, thereby rendering the bowel more susceptible to triggering infection later in life. Knowledge about risk factors for appendicitis is, however, poor, and the roles of diet, housing, and amenities such as hot water and bathroom facilities are doubtful. Because breast-feeding can modify the exposure or the type of immune response to some microbial agents during infancy, we investigated the relation between infant feeding and acute appendicitis in this case study.

Financial or Other, Competing Interest: None.

Submission 01-11-2016, Peer Review 20-12-2016,

Acceptance 26-12-2016, Published 02-01-2017.

Corresponding Author:

Dr. Raghupathy,

Professor,

Department of General Surgery,

Chengalpattu Medical College and Hospital,

Chengalpattu.

E-mail: dr.traghupathy@gmail.com

DOI: $10.14260 /$ jemds $/ 2017 / 9$

\section{(c) $(1) \odot$}

Because breast-feeding confers many important health and other benefits, including psychosocial, economic, and environmental benefits, it is not surprising that breast-feeding has been recommended by several prominent organisations of health professionals. Among them, the American Academy of Paediatrics, American Academy of Family Physicians, College of Obstetricians and Gynaecologists, College of NurseMidwives, American Dietetic Association, and American Public Health Association, all of which recommend that most infants in the United States be breastfed for at least 12 months. These organisations also recommend that for the first six months, infants be exclusively breastfed, meaning they should not be given any food or liquid other than breast milk, not even water.

Regarding nutrient composition, the American Dietetic Association stated, "Human milk is uniquely tailored to meet the nutrition needs of human infants. It has the appropriate balance of nutrients provided in easily digestible and bioavailable forms.[1][2]"

The AAP stated, "Human milk is species-specific, and all substitute feeding preparations differ markedly from it, making human milk uniquely superior for infant feeding. Exclusive breastfeeding is the reference or normative model against which all alternative feeding methods must be measured with regard to growth, health, development, and all other short- and long-term outcomes."

While breast-feeding is recommended for most infants, it is also recognised that a small number of women cannot or should not breast-feed. For example, AAP states that breastfeeding is contraindicated for mothers with HIV, human T-cell lymphotropic virus type 1 or type 2 , active untreated 
tuberculosis, or herpes simplex lesions on the breast. Infants with galactosaemia should not be breastfed. Additionally, the maternal use of certain drugs or treatments, including illicit drugs, antimetabolites, chemotherapeutic agents, and radioactive isotope therapies, are the causes for not breastfeeding.

\section{Objectives of the Study}

To study the relation between breast-feeding and acute appendicitis correlating with HPE report to enhance the quality of the study.

\section{MATERIALS AND METHODS}

All 68 cases admitted to Chengalpattu Medical College and Hospital, Tamilnadu, between 1 January and 30 November 2016 with histologically confirmed acute appendicitis were recruited for the study. All these cases were living in and around Chengalpattu area. Their mothers were interviewed during the stay in hospital by our study group with proper consent, with keeping objectives of the study in mind. Stratified analysis showed that no factor among those we analysed (Birth weight, sex, type of delivery, maternal education, and number of other children in the household) confounded or modified the association between feeding and illness.

\section{RESULTS}

In our study conducted in Chengalpattu Medical College, 88\% of the people affected with acute appendicitis were breast-fed for duration less than or equal to 12 months. Low birth weight babies are more prone for appendicitis. Data from our study given below in table.

\begin{tabular}{|c|c|c|}
\hline Characteristics & Cases & $\%$ \\
\hline Sex & & \\
\hline Male & 52 & 76.47 \\
\hline Female & 16 & 23.52 \\
\hline Mean age (yrs.) & 8.6 & \\
\hline Birth Weight (kg) & & \\
\hline$>2.5$ & 21 & 30.88 \\
\hline$<2.5$ & 47 & 69.11 \\
\hline Type Of Delivery & & \\
\hline Vaginal & 59 & 86.76 \\
\hline Caesarean & 9 & 13.23 \\
\hline Breast-feeding (Months) & & \\
\hline Never & 0 & 0 \\
\hline $0-3$ & 31 & 45.58 \\
\hline $4-6$ & 18 & 26.47 \\
\hline $6-12$ & 11 & 16.17 \\
\hline$>12$ & 8 & 11.76 \\
\hline
\end{tabular}

\section{DISCUSSION}

The health effects of breast-feeding are well recognised and apply to mothers and children in developed nations such as the United States as well as to those in developing countries. Breast milk is uniquely suited to the human infant's nutritional needs and is a live substance with unparalleled immunological and anti-inflammatory properties that protect against a host of illnesses and diseases for both mothers and children.
In 2007, the Agency for Healthcare Research and Quality published a summary of systematic reviews and metaanalyses on breastfeeding and maternal and infant health outcomes in developed countries. The AHRQ report reaffirmed the health risks associated with formula feeding and early weaning from breast-feeding.[3] With regard to short-term risks, formula feeding is associated with increases in common childhood infections, such as diarrhoea and ear infections. The risk of acute ear infection, also called acute otitis media, is 100 percent higher among exclusively formula-fed infants than in those who are exclusively breastfed during the first six months.

The risks associated with some relatively rare but serious infections and diseases such as severe lower respiratory infections and leukaemia are also higher for formula-fed infants. ${ }^{[4][5]}$ The risk of hospitalisation for lower respiratory tract disease in the first year of life is more than 250 percent higher among babies who are formula fed than in those who are exclusively breastfed at least four months. Furthermore, the risk of sudden infant death syndrome is 56 percent higher among infants who are never breastfed. For vulnerable premature infants, formula feeding is associated with higher rates of necrotising enterocolitis. The AHRQ report also concludes that formula feeding is associated with higher risks for major chronic diseases and conditions, such as type 2 diabetes, asthma, and childhood obesity, all three of which have increased among U.S. children over time.[6]

Compared with mothers who breast-feed, those who do not breast-feed also experience increased risks for certain poor health outcomes.[7][8] For example, several studies have found the risk of breast cancer to be higher for women who have never breastfed. Similarly, the risk of ovarian cancer was found to be 27 percent higher for women who had never breastfed than for those who had breastfed for some period of time. $^{2}$ In general, exclusive breast-feeding and longer durations of breast-feeding are associated with better maternal health outcomes. ${ }^{[9]}$

Breast-feeding stimulates a more tolerant lymphoid tissue at the base of the appendix and this could provide protection against acute appendicitis. Two studies reported that children and adolescents with appendicitis were less likely to have been breast fed.[10] In a case-control study of 200 children with histologically confirmed acute appendicitis matched by 200 siblings with the same sex and different age - up to three-yearold, we found breast-feeding in at least the first two months of life and for more than four months provides protection against acute appendicitis. These findings suggest that breast-feeding may possibly give protection against the development of appendicitis.

\section{CONCLUSION}

The risk of developing appendicitis is higher among children who never received EBF and who were breastfed for less than 12 months.

\section{REFERENCES}

[1] Heaton KW. Aetiology of acute appendicitis. BMJ 1987;294(6588):1632-3.

[2] Barker DJ. Acute appendicitis and dietary fibre: an alternative hypothesis. BMJ 1985;290(6475):1125-7. 
[3] Nelson M, Morris J, Barker DJ, et al. A case-control study of acute appendicitis and diet in children. J Epidemiol Community Health 1986;40(4):316-8.

[4] Coggon D, Barker DJ, Cruddas M, et al. Housing and appendicitis in Anglesey. J Epidemiol Community Health 1991;45(3):244-6.

[5] Goldman AS. The immune system of human milk: antimicrobial, anti-inflammatory and immunomodulating properties. Pediatr Infect Dis J 1993;12(8):664-71.

[6] Oddy WH, Kendall GE, Blair E, et al. Breast-feeding and cognitive development in childhood: a prospective birth cohort study. Paediatric and Perinatal Epidemiology 2003;17(1):81-90.
[7] Burns N, Grove SK. Understanding nursing research. Philadelphia: W.B. Saunders Co 2003.

[8] Concato J, Jain A, Leventhal JM. How good is the evidence linking breastfeeding and intelligence? Pediatrics 2002;109(6):1044-53.

[9] Gale CR, Martyn CN. Breastfeeding, dummy use, and adult intelligence. Lancet 1996;347(9008):1072-5.

[10] Mortensen EL, Michaelsen KF, Sanders SA, et al. The association between duration of breastfeeding and adult intelligence. Journal of American Medical Association 2002;287(18):2365-71. 